\title{
Transporte e mercado imobiliário: uma lógica urbana sustentável? Estudo sobre o Transmilênio, Bogotá
}

\author{
Johann Dilak Julio Estrada \\ Secretaria Distrital do Habitat, Bogotá, Colômbia / Universidade Externado de Colômbia
}

Fábio Duarte

Pontifícia Universidade Católica do Paraná

\begin{abstract}
Legal instruments of land use, such as urban valuation and right-to-build taxation, or great public investments in infra-structure have important impacts on the quality of the urban environment sometimes not predicted once those instruments and investments were implemented. In this article we analyse how the important innovations on the public transportation system of Bogotá, Colombia, that turn the city into a world reference on the subject, at the same time have caused indirect transformations in traditional urban areas which now live a degradation that can be perceived in the real state market.
\end{abstract}

RESUMO: Instrumentos de gestão do uso do solo, tais como as contribuições por valorização, a participação em maisvalias urbanas, assim com os grandes investimentos públicos têm uma importante repercussão nos ambientes criados pela normativa urbana das cidades, por vezes imprevistos quando da aplicação desses instrumentos. Neste artigo analisamos como as inovações no transporte público de Bogotá - que trouxeram uma eficiência ao sistema de transportes que colocou a cidade como referência internacional - causaram ao mesmo tempo as transformações indiretas na ocupação urbana na área afetada que hoje vive um processo de depreciação imobiliária e urbanística.

\section{INTRODUÇÃO}

Os instrumentos de gestão do uso e ocupação do solo têm uma grande repercussão nos ambientes criados pela normativa urbana. Quando utilizados de forma separada ocasionam vazios e rompimentos da dinâmica urbana. Nessas ocasiões vê-se comumente uma disputa velada entre, de um lado, a dinâmica estatal, que com sua força e legitimidade tenta dar rumo e forma a uma aglomeração urbana, e de outro a dinâmica privada, que por sua vez busca canalizar em beneficio próprio os impulsos do estado.

Parece claro como um investimento em matéria de transporte, seja a construção de uma nova via, seja a regeneração de uma antiga, valoriza o solo ao seu redor. Neste artigo, porém, tentaremos apresentar o contrário: como um investimento em infraestrutura viária e sistema de transporte trouxe um impacto negativo numa determinada área urbana, tanto no uso e ocupação do solo como no mercado imobiliário que a compõe. Como estudo de caso, tomaremos a implantação do Transmilênio, em Bogotá, Colômbia.

\section{CARÁTER DOS INSTRUMENTOS DE USO DO SOLO}

A inter-relação dos elementos da administração local, do transporte e do mercado (especialmente do mercado imobiliário) nem sempre se apresenta em um mesmo momento e de forma articulada, o que ocasiona fissuras na construção da cidade. Toda vez que a ação do governo local não contempla (ou enfrenta) a lógica privada, os resultados de uma determinada ação podem levar a uma situação de desvalorização dos imóveis e de ruptura da lógica urbana.

O princípio é de que determinado investimento público em transporte valorizará a região, e que o valor do solo urbano diminuiria na medida na medida em que estes se distanciassem do empreendimento viário implantado. São empreendimentos realizados sob um amplo conjunto de políticas e instrumentos relacionados a atividades fiscais e de planejamento do uso do solo (Smolka e Amborski, 2001). Esses investimentos, ao mesmo tempo em que tentam prover de serviços a comunidade, têm como objetivo a idéia da captura de mais-valias fundiárias. 
Como os mesmos autores o propõem:

A captura de mais-valias é referente ao processo pelo qual o todo o uma parte dos incrementos de valor de terra, atribuídos ao "esforço da comunidade" são recuperados pelo setor publico, seja por sua conversão em receitas públicas através de impostos, contribuições, exações e outros meios fiscais, ou mais diretamente, em melhorias locais para o beneficio da comunidade (Smolka e Amborski, 2001).

$\mathrm{Na}$ continuação do argumento, evidenciam que em regra esses incrementos resultam de ações feitas pelo setor público e que obedecem a valores criados pelo desenvolvimento de infra-estrutura física em um local determinado.

As políticas de captura de mais-valias surgidas de investimentos públicos podem estar apoiadas em três categorias de instrumentos, como o estabelecem Smolka e Amborski: duas de caráter fiscal, como impostos e contribuições, e uma terceira por meio de instrumentos reguladores. Os instrumentos de caráter fiscal exigem que, para a captura do valor pelo setor público, o proprietário do bem pague um imposto ou contribuição. Por outra parte, os instrumentos reguladores levaram a alguma forma de beneficio público que seja paga pelo proprietário em razão do incremento do valor de sua propriedade.

Para nosso interesse cabe ressaltar que as contribuições fiscais têm um largo prontuário na América Latina, já que:

\section{Quase todos os paises latino-americanos possuem preceitos legais, em nível na- cional, que autorizam alguma variante de contribuição ou taxa de valorização (Contribuição de Melhoria) para permitir que o setor público capture os incrementos de valor da terra associados a investimen- tos públicos (Smolka e Amborski, 2001).}

Os instrumentos fiscais de captura de mais-valias podem ter uma relação direta com a tributação sobre o valor da terra, por isso se faz necessário identificar estas mais-valias no sentido restrito de captura de incrementos de valor associados a intervenções públicas específicas. No que se refere à captura das mais-valias e à provisão de infra-estrutura urbana, se faz necessário estabelecer o universo futuro que um investimento em infra-estrutura poderá trazer a um determinado território, assim como as formas como serão cobradas as mais-valias, uma vez que o proprietário pretenda obter o beneficio do investimento público na conseqüente valorização do bem. No caso contrário, em que seja detectada a perda do valor do imóvel, o proprietário poderá reclamar ante a autoridade pertinente.

A respeito dos instrumentos reguladores podemos ver claramente como a participação em maisvalias é:

Um direito público legal de "participar" de uma parcela de $30 \%$ a $50 \%$ da avaliação das mais-valias fundiárias que resultem de ações administrativas, tais como mudanças na designação e qualificação da terra (de rural para urbana, por exemplo), no zoneamento ou em autorizações de aumento de densidade, que geram ganhos substantivos para o proprietário (Barco de Botero e Smolka, 2000).

Algumas vezes, a captura de mais-valias é alcançada, mas com resultados redistributivos perversos ou negativos. Isto acontece toda vez que se apresentam casos em que os planejadores aplicam instrumentos de captura de mais-valias sem entender inteiramente seus impactos, levando à ocorrência de alguns impactos inesperados e às vezes indesejados, já que a aplicação de instrumentos de captura de mais-valias não leva necessariamente a efeitos positivos na quantidade total de valor que é tributado ou recuperado, na quantidade total de infra-estrutura que é financiada, ou na capacidade de controle do uso do solo (Smolka e Amborski, 2001).

Em particular no caso ora apresentado, há uma combinação de fatores que podem ter influenciado a dinâmica urbana atual dentro de um setor especifico, como o caracterizamos acima, pela má utilização dos instrumentos de captura de mais-valias, como também pela transformação da lógica urbana ao interior do setor, em grande parte relacionada à mudança do sistema de transporte público. Não se trata de buscar responsáveis, mas a situação do local dá conta de que algo não está operando na articulação de políticas e instrumentos do ordenamento territorial e urbano, em especial com os relacionados com a gestão e uso do solo (Lopes, 1998).

\section{TRANSMILÊNIO E DINÂMICA URBANA}

Um das vias mais representativas da cidade de Bogotá é o eixo viário conhecido com o nome de Avenida Caracas (ver Figura 1, adiante). Nos anos 1990, essa via foi objeto de uma reestruturação de caráter conceitual e físico do sistema de transporte, que contemplou a separação do fluxo de veículos, dotando os ônibus de serviço público de caneletas de trânsito exclusivo, com estações designadas nas quais os usuários deveriam esperar em forma organizada as distintas rotas de ônibus que os 
conduziriam a seu destino. Esse novo sistema foi batizado Transmilênio, e tornou-se internacionalmente conhecido na área de transportes.

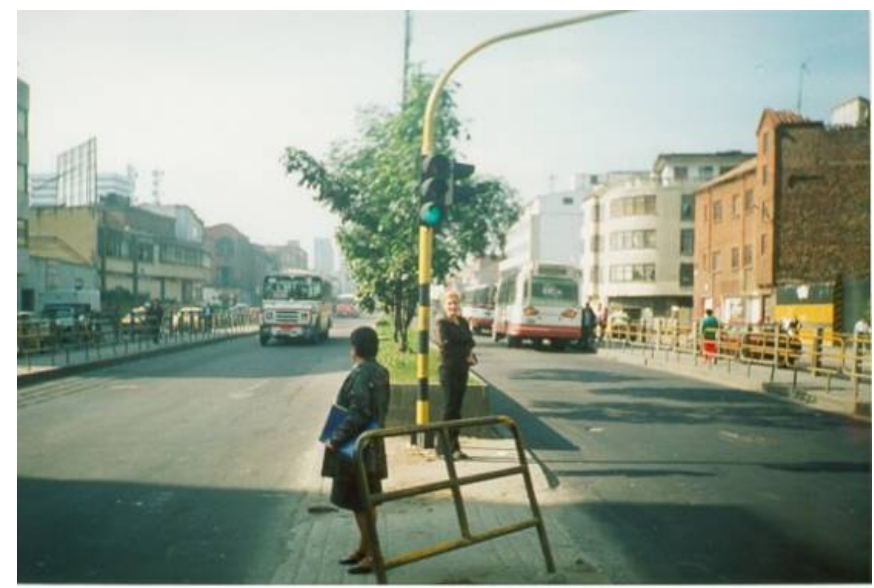

Figura 1: Antiga Avenida Caracas (foto sentido Norte-Sul)

Fotografia: Johann Dilak Estrada

Até então, a entrada no sistema de transporte era aberta, o sistema de cobrança era dentro do ônibus e a dinâmica da via se integrava ao setor econômico da zona. Os engarrafamentos gerados pela oferta excessiva de ônibus geravam um nó de integração do espaço construído com a rotina dos usuários e moradores do setor.

Ao longo do eixo se concentrou um comércio de passagem, que se nutria de forma direta da necessidade dos pedestres de utilizar os calçadões para ingressar no sistema. No setor que abarca os limites da Rua 19, do centro da cidade à Rua 26, ao longo do eixo (respectivamente, AC 19, AC 26 e AK 14 no Mapa 1) em sentido norte, no setor em enquadramento, esse comércio teve seu auge em forma de lojas de autopeças. Isso se deu em parte pela permissibilidade das normas urbanísticas como dos controles do trânsito em geral e em particular de estacionar na canaleta de uso particular. É necessário estabelecer que a região no enquadramento faz parte do Central Business District (CBD, centro de negócios) de Bogotá.

As estações ou paradas, quando abertas, possibilitavam o ingresso dos usuários no sistema no sentido em que estes efetuariam as viagens, ou seja, o sentido norte-sul era totalmente independente do sentido sul-norte. Podemos também estipular que pela lógica da "guerra do centavo" em que vivia o eixo, quando cada empresa estipulava o valor da passagem em uma disputa de centavos para conseguir passageiros, a superlotação de ônibus, em ambos os sentidos, gerava uma dinâmica urbana bem particular na medida em que sempre existiu um tráfego constante tanto de ônibus como de pedestres que dotavam de vida o local - o que a sua vez permitia a continuação do ciclo econômico do território.

Outro fator relevante tem a ver com a multiplicidade de rotas de transporte que circulavam pelo corredor, que se tornara como um carrefour, ou nó de integração da cidade, situação que fazia com que muitas das viagens interurbanas tivessem como destino ou origem esse setor da cidade.

O CONPES - Consejo Nacional de Política Económica y Social (a máxima autoridade nacional de planejamento) estabeleceu uma clara vocação do governo nacional e local de Colômbia na definição de uma estratégia para a consolidação de um sistema de serviço urbano público de transporte de passageiros para a cidade de Bogotá.

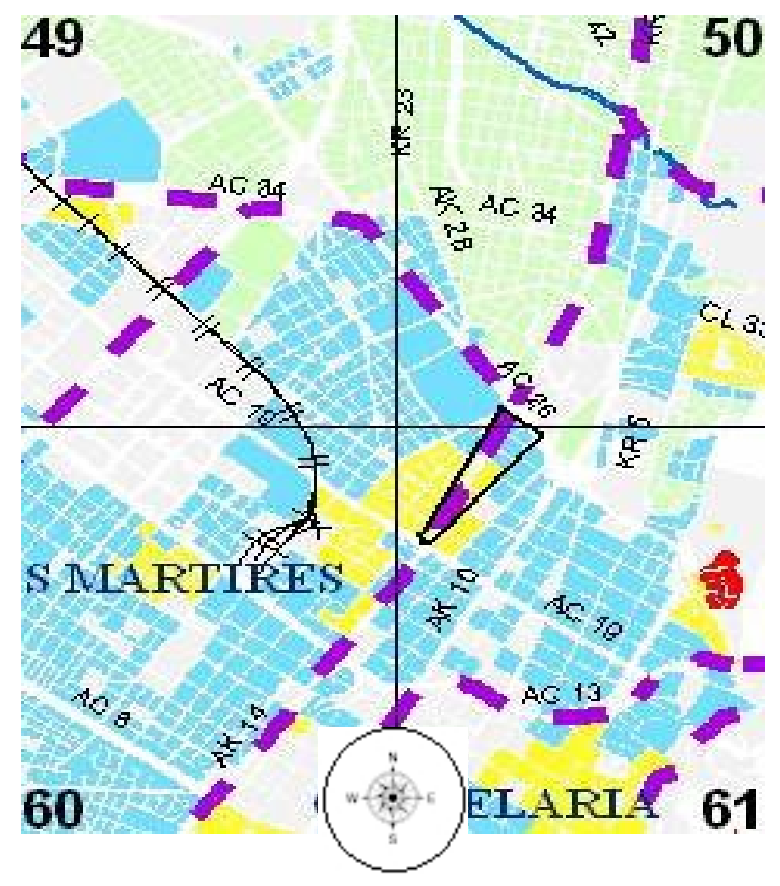

Figura 2: Mapa esquemático da área em estudo

Tal estratégia se materializou na construção do sistema Transmilênio. A lógica deste sistema contempla uma mudança radical no sistema de estações, na forma de acesso ao sistema, como também na coleta da passagem (Figura 3). Observe-se que a alteração, além de eliminar a concorrência entre veículos e racionalizar a oferta de serviço, integra os sentidos de viagem em estações de embarque-edesembarque no centro da via.

Essa nova forma de acesso ao sistema originou uma transformação da antiga dinâmica de rastro - onde a movimentação intrínseca do sistema de transporte alterava a dinâmica urbana lindeira - para a consolidação do que na teoria de redes se conhece como efeito túnel - ou seja, o sistema de transporte funciona com o mínimo de interferência com seu entorno imediato. Isto fez com que antigas referências do comércio de passagem - que existiam 
no setor - fossem alijadas do sistema, uma vez que a lógica da rede agora limita o acesso às estações e não vincula o acesso aos ônibus com o calçadão mais próximo, ou seja, com a vida comercial do setor.

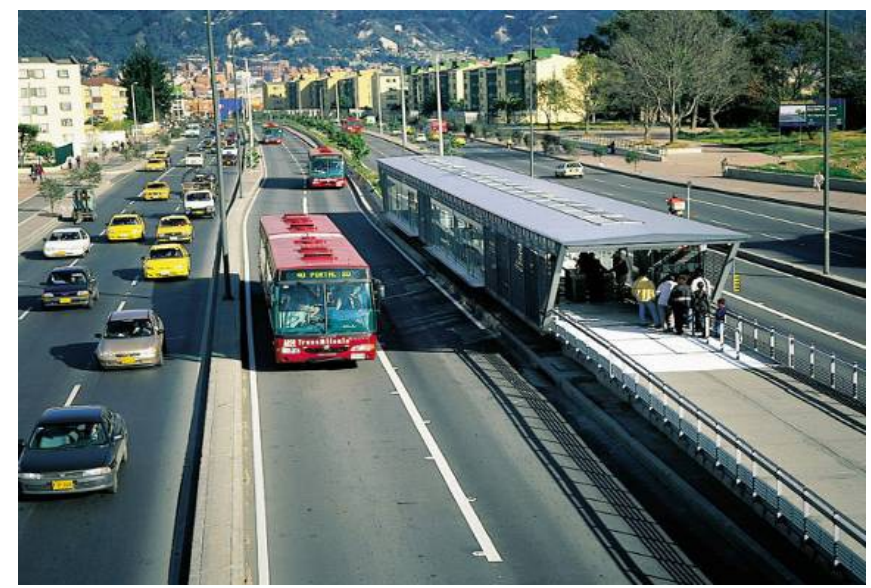

Figura 3: Sistema de estações do novo sistema Transmilênio

Fotografia: Fábio Duarte

A antiga relação de permeabilidade do transporte coletivo com o seu entorno foi responsável pela valorização comercial de seus imóveis e movimentava o mercado imobiliário (Parias e Luna, 2002). Com a implantação no novo sistema de transporte, as antigas relações permissivas e obscuras entre órgãos públicos e interesses privados foram eliminadas; porém, também se eliminou com a forma escolhida para a implantação do sistema, a permeabilidade entre o sistema de transporte e o comércio local.

Esta situação acarretou em uma dinâmica perversa para o mercado, pois não houve a valorização esperada decorrente de um novo sistema de transporte público inegavelmente mais eficiente. Não se trata aqui de questionar a eficiência e benefícios sociais do sistema de transporte, mas de verificar que, quando visto integrado ao uso do solo e ao mercado imobiliário, vê-se que os benefícios não se traduziram de forma significativa nem para os ocupantes nem para aos proprietários dos imóveis ao longo da via. Afinal, já não é necessário transitar pelo calçadão (passeio público) se o usuário se encontra dentro do sistema (Figura 4).

Dessa forma podemos observar como a vida comercial do setor era amplamente dependente da antiga inter-relação da lógica do eixo viário, neste caso representado pelo transporte e sua forma de operação com o uso do solo arraigado no local.

Ao longo do eixo do sistema, no enquadramento assinalado no mapa esquemático da Figura 2, é freqüente ver cartazes com a consigna de VENDE-
SE ou ALUGA-SE. Situação totalmente inesperada depois da revitalização da via, do sistema dos calçadões e do investimento de aproximadamente 3,8 milhões de dólares (valores de 2000) por quilômetro construído de infra-estrutura viária da primeira fase do sistema Transmilênio.

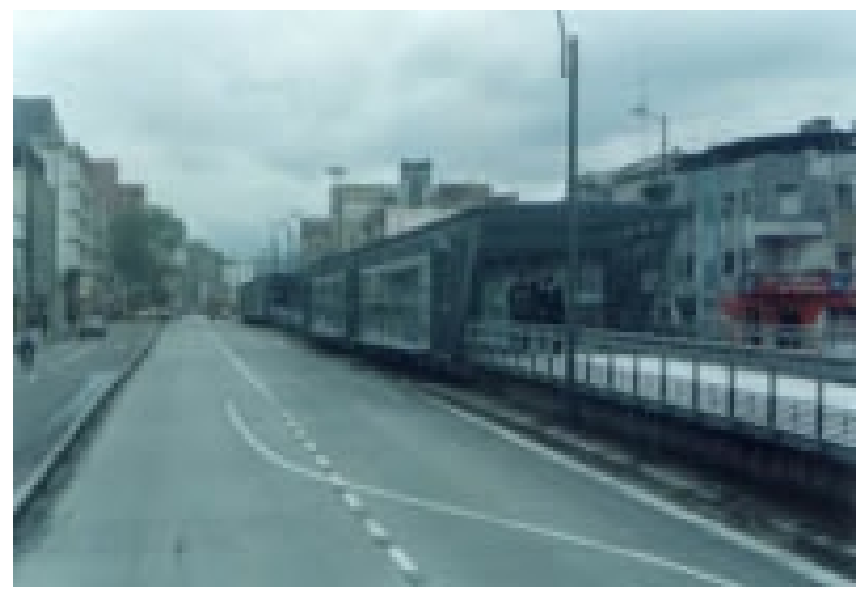

Figura 4: Estação da Rua 22 com acesso na Rua 20 e 22

Fotografia: Johann Dilak Estrada

As obras da primeira fase do sistema Transmilênio, fase na qual estava contemplado o eixo da Avenida Caracas, ocorreram entre 1998 e 2000 . É claro que os resultados obtidos após o investimento viário não foram os esperados, uma vez que o conceito por valorização do solo captado pelos imóveis ao lado da via, junto com a mudança da lógica urbana (comércio de passagem) no setor, ocasionaram um êxodo da região.

As seguintes fotografias de autoria de Johann Dilak Julio Estrada (Figuras 5 a 8) mostram o que acontece no setor compreendido entre as Ruas 26 e 19, ao longo do eixo da Avenida Caracas.

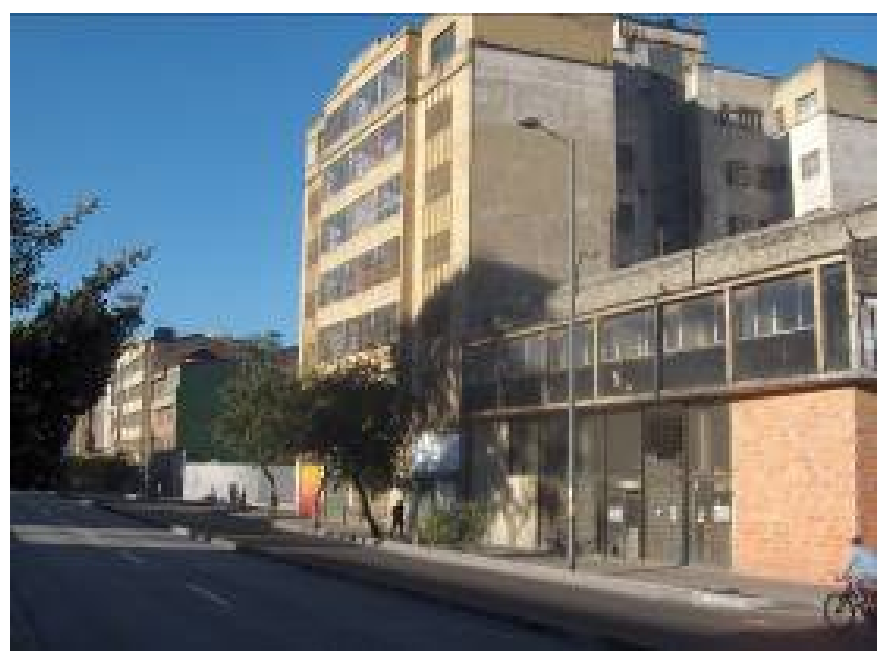

Figura 5: Imóveis desocupados junto ao Transmilênio 


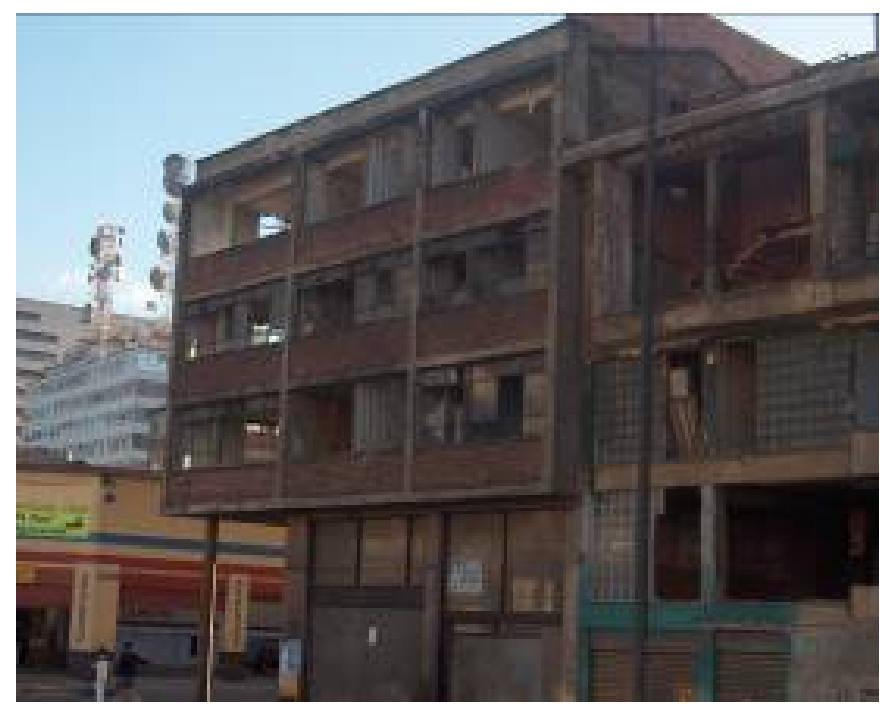

Figura 6: Imóveis inacabados junto ao Transmilênio

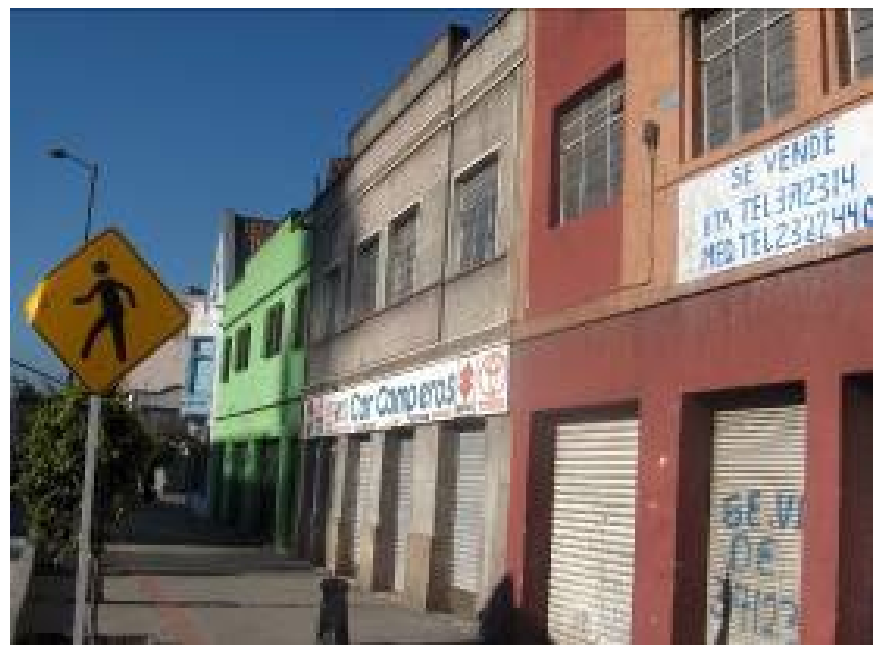

Figura 7: Imóveis desocupados à venda junto ao Transmilênio

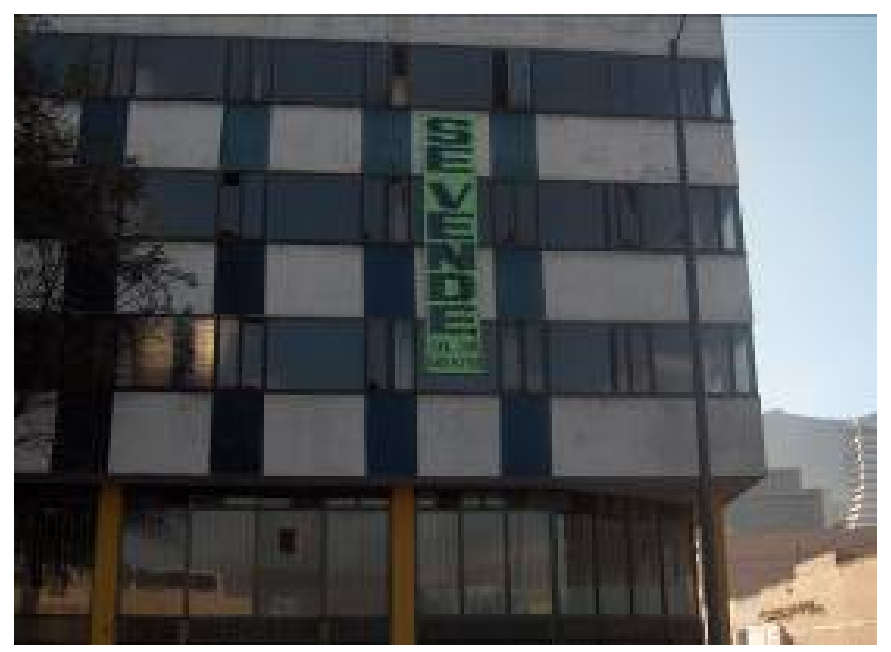

Figura 8: Imóveis desocupados à venda junto ao Transmilênio
Os vazios urbanos proliferam no setor e não são poucas as construções em total estado de abandono e deterioração. Podemos observar igualmente antigas lojas de autopeças em geral fechadas, que servem como bodegas ou simplesmente sem nenhum uso aparente.

É necessário deixar claro que o centro de Bogotá vem atravessando um fenômeno de esvaziamento progressivo e perda de dinâmica urbana desde a década de 90; mas a operação setorizada do transporte, ao invés de reverter o crescente êxodo por parte dos comerciantes do setor, tornou-se também responsável, por meio do rompimento da dinâmica do setor, com o processo de deterioro do setor em observação.

Ao mesmo tempo em que a iniciativa estatal lançava o projeto Transmilênio, em julho de 1997 foi estabelecida a Lei n. 388 de desenvolvimento territorial, pela qual se modificou a Lei de reforma urbana, a $9^{a}$ de 1989 , e a Lei $3^{\text {a }}$ de 1991 . Essa lei contempla entre seus principais objetivos:

- o estabelecimento dos mecanismos que permitam ao município, em exercício de sua autonomia, promover o ordenamento de seu território;

- o uso eqüitativo e racional do solo;

- a execução de ações urbanísticas eficientes;

- garantir que a utilização do solo por parte de seus proprietários seja ajustado à função social da propriedade; e,

- a execução de atuações urbanas integrais.

A Lei 388/1997 é ainda objeto constante de correções e decretos que procuram delimitar o escopo dos instrumentos de gestão e uso do solo que propõe. Sobretudo no caso da capital, o plano de ordenamento territorial que propõe a lei foi objeto de revisão ao longo de 2003 por parte de entidades da ordem nacional, regional e local (Decreto 469 de 2003 - Revisión POT).

Nessa lei são estipuladas as disposições referentes à participação nas mais-valias urbanas decretando que os cidadãos têm direito a participar do aumento do valor da terra criado socialmente por ações administrativas. A lei também estabelece que as entradas de recursos financeiros provenientes das mais-valias deverão ser utilizadas principalmente para a provisão de infra-estrutura e moradias de interesse social, assim como para obras públicas de interesse geral.

Cabe ressaltar que a captação de taxas e contribuições por conceito de incrementos no valor do solo não são novas na Colômbia, já que desde o início do Século 20 foram instituídas como uma clara ajuda 
para o desenvolvimento de obras de infra-estrutura pública nas cidades (Doebele, 1998). Podemos ver como exemplo a Contribuição por Valorização, que no caso de Bogotá foi amplamente implementada no período de industrialização e crescimento urbano da cidade, sobretudo na última metade da década dos anos 1960, continuando em menor ritmo nos anos 1970 e 80 . O instrumento teve uma queda em sua utilização em grande parte pela diminuição da vontade política de utilizá-lo com também pela dificuldade de estabelecer o impacto real dos investimentos públicos nos terrenos privados.

Isto se deve a não haver termos estritamente econômicos que fundamentem solidamente a idéia que espontaneamente aparece tão evidente: a idéia de que o valor dos investimentos públicos é transmutado nos preços dos terrenos privados, e, portanto, que existe uma identidade quantitativa entre o investimento público e o incremento nos preços imobiliários privados, uma vez que o impacto do investimento nos lotes não tem uma relação muito estreita com a somatória de tal investimento. Já que esse impacto pode ser maior ou menor, e pode inclusive ser negativo, e ainda - e mais comum - que afete alguns lotes positivamente e outros de forma negativa. Segundo Jaramillo (2001), o caso perfeito parece ser o encontrado em nossa área de estudo:

Un ejemplo para ilustrar esto: una gran vía de transporte urbano puede afectar positivamente los terrenos aledaños porque aumenta su accesibilidad; pero a nível urbano, puede homogeneizar la accesibilidad de todos los terrenos de la ciudad y hacer disminuir el componente del precio que se deriva de estas diferencias (y que es lo que en general justifica estas obras); los terrenos cercanos pueden ser afectados con muy diversa intensidad, ya que en algunos casos puede permitir otros usos urbanos que generan rentas de una magnitud mucho mayor (por ejemplo, zonas residenciales que pasan a ser comerciales, etc.). Pero incluso una obra de estas puede afectar negativamente el precio de los terrenos anexos: si entorpece un uso que generaba rentas superiores (por ejemplo, una zona comercial de lujo que se ve desestructurada por una vía de transporte rápido)" (Jaramillo, 2001).

A partir de 1994, ante uma crise fiscal e a impossibilidade de aceder a créditos para o financiamento de obras, as administrações públicas municipais revitalizaram o instrumento de contribuição por valorização com o fim de captar em benefício geral rendas produzidas pelo incremento do valor do solo na cidade. Estipularam que se pagaria a contribuição em proporção às características do imóvel, dando um maior valor a terrenos vazios e de uso não residencial. A medida teve um êxito limitado, em grande parte pelo fato de a contribuição estar ligada ao imposto progressivo territorial urbano (IPTU) e precisar de bases cadastrais sólidas e ferramentas de gestão de uso e ocupação do solo, além de avaliações imobiliárias confiáveis - o que, em Bogotá, distavam muito na realidade dos parâmetros estipulados pela normatividade. Essa situação deu origem a uma série de reclamos por parte dos cidadãos, que exerceram pressão sobre grupos de interesse nos órgãos de eleição popular e conseqüentemente na vontade política sobre o grau e a forma de aplicação do instrumento (Jaramillo, 2001).

Voltando ao assunto das mais-valias urbanas, devemos enfatizar que este novo instrumento de participação municipal nasce não para substituir o mecanismo de contribuição por valorização, senão com a intenção de complementar e atingir casos em que a contribuição não operava satisfatoriamente. A definição do instrumento parte da mesma lógica da contribuição por valorização, como foi explicado acima, mas com a diferença substancial. Na aplicação do novo conceito, o valor a ser cobrado não se subordina ao valor do investimento estatal, e sim se estabelece em uma porcentagem (de $30 \%$ a $50 \%$ ) do incremento real do preço de mercado do imóvel e que terá efeito uma vez que se conte como o aval estatal para realizar uma construção ou uma reforma do uso do imóvel.

Assim, a participação em mais-valias pretende captar pelo menos uma parte dos incrementos nos preços dos imóveis que sejam beneficiados por uma decisão estatal no âmbito territorial. Por essa razão foram estabelecidos três fatos que geram a participação em mais-valias e que consistem em decisões administrativas que configuram ações urbanísticas: o primeiro fato pode ser o estabelecimento de modificações ao zoneamento do uso do solo que tenham como conseqüência um incremento nos preços do solo; o segundo, a autorização de um maior aproveitamento do solo em edificação, seja em termos de elevação do índice de ocupação, seja de construção; e terceiro, a execução de obras públicas por parte do Estado que afetem positivamente os preços dos terrenos.

Este último fator é complicado de implementar, já que a correta incorporação do mecanismo de participação em mais-valias requer instrumentos de gestão do uso e ocupação do solo altamente apurados, em especial bases cadastrais sólidas e atualizadas que permitam conhecer o valor do solo urbano na cidade antes e depois do investimento e da compra 
do imóvel (Martinez, 2004). Essas condições estão muito distantes das possibilidades do aparelho estatal e local, confirmando uma vez mais a distância entre as ferramentas legais de gestão do solo e a realidade e condições dos insumos para fazê-los efetivos.

Sintetizando, é possível observar que, por uma parte, a normativa legal estruturada para o benefício geral, junto como a vontade política de reestruturação do sistema de transporte, levou a uma carga impositiva para um setor e uma dinâmica urbana que não se encontravam em condições de enfrentar maiores cargas tributárias. Tudo somado, gerou-se um êxodo da atividade econômica caracterizada no setor em direção a outros locais da cidade, já que não mais era rentável permanecer no setor. Toda vez que a intenção e a lógica estatal-legal foram antepostas sobre a lógica econômica, gerou efeitos perversos para um conjunto significativo da sociedade.

$\mathrm{Na}$ lógica estatal, durante o período em que foi feito o empreendimento viário, os proprietários de imóveis no setor deviam pagar pelo investimento em razão da valorização que seria obtida. Agora, depois da finalização da obra, também é o setor o alvo potencial de um processo redistributivo de valor, já que qualquer empreendedor que deseje efetuar uma obra em um dos imóveis à venda, deverá recolher ao Estado, por meio do instrumento de participação em mais-valias, alguma percentagem do incremento de valor apropriado em teoria pela valorização dos imóveis. Devemos aclarar que o novo instrumento atua como um condicionante para quem tivesse um interesse econômico em alguns dos locais do setor, uma vez que não poderia especular com o imóvel em razão do valor da contribuição por valorização. Por outra parte, o incremento no preço comercial do solo, uma vez feita uma construção ou reforma, dependeria da dinâmica social e econômica que se desenvolva no setor.

Pelo que está estipulado na legislação sobre a participação em mais-valias, o local ainda não é um alvo claro da lógica econômica pois a taxa interna de retorno dos investimentos não estaria garantida, deixando aberto que o futuro do setor, no que se refere à lógica urbana, encontra-se ligada ao que o Estado, no seu contínuo método de ensaio e erro, estabeleça.

O trabalho conjunto que deveria existir entre agentes públicos e privados para a correta implementação da normatividade e ferramentas do uso do solo só existe no mundo das idéias. A desarticulação das políticas e iniciativas estatais com respeito ao ritmo da vida de um local e à lógica econômica produz situações inesperadas na cidade, o que obriga os planejadores urbanos a estruturar novos instrumentos e estratégias para tentar recuperar o local. O êxito ou o fracasso das novas políticas dependerão da possibilidade do Estado de integrar um número maior de agentes ao jogo de articulações que supõe o processo de criação da cidade.

A nova dinâmica que surge no setor coloca os agentes econômicos à espera de possíveis novos rumos na disposição do uso do solo e na determinação por parte do governo local de estratégias que incitem a mudança do setor. Estas ações poderiam acontecer em forma de processos de renovação urbana e requalificação do uso do solo no setor, como também baixo a forma de grandes operações urbanas, realizadas pelo mesmo Estado em consórcio com empreendedores privados e centradas em projetos comercias e de moradia.

\section{CONSIDERAÇÕES FINAIS}

Atualmente, o governo de Bogotá, em colaboração com agentes públicos e privados, empreende ações orientadas à recuperação do setor, em especial um plano de zoneamento do centro da cidade, com o objetivo de recuperar o CBD. Busca-se torná-lo atrativo para agentes que no passado se deslocaram para outras áreas da cidade por comodidade, segurança ou para a obtenção de maiores rendimentos (Figura 9).

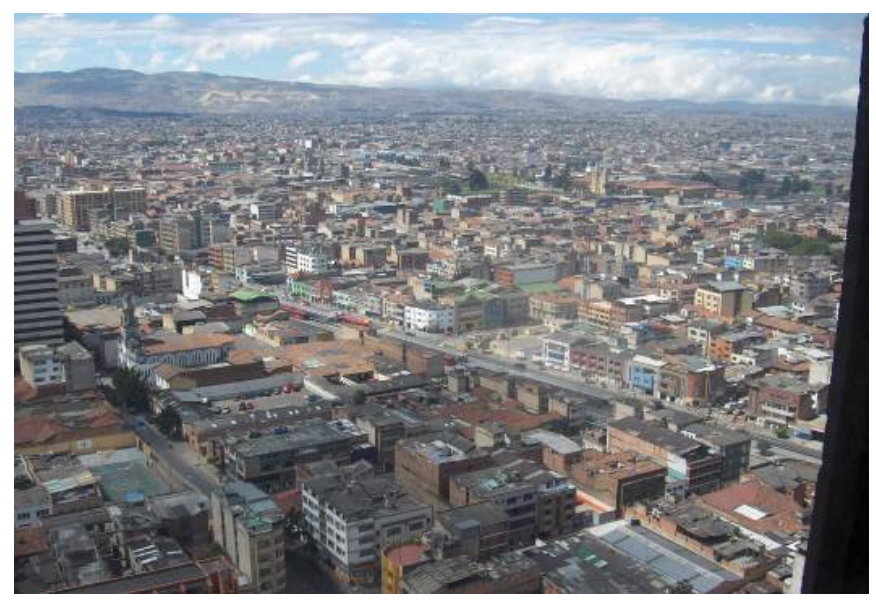

Figura 9: Fotografia aérea do setor categorizado

Pela constatação dos arquivos existentes da formulação do plano para a revitalização do centro de Bogotá, este se encaixa na definição que o Estatuto da Cidade brasileiro (BRASIL, 2001) prevê para uma operação urbana consorciada. Esta constitui um tipo especial de intervenção urbanística voltada para a transformação estrutural de um setor da cidade, envolvendo simultaneamente o redesenho deste setor (tanto no espaço público como privado); a combinação de investimentos privados e públicos para sua execução e alteração, manejo e transação dos direitos de uso e edificabilidade do uso e obrigações de urbanização. Trata-se, portanto, da reconstrução 
e redesenho do tecido urbanístico, econômico e social de um setor especifico da cidade que pode ser efetuada por meio de parcerias entre proprietários, poder público, investidores privados, moradores e usuários permanentes. E o mais importante é que estas intervenções podem se dar através do estabelecimento de um marco regulatório completamente diferente daquele em vigor para o conjunto da cidade, o que muda as obrigações dos agentes públicos e privados envolvidos.

A pergunta que se deve fazer é: o que passará com os atuais habitantes do setor? Terão que se resignar e se deslocar em direção a áreas que se encontrem ainda à sombra da legalidade urbana?

Em salvaguarda da função social da propriedade se faz indispensável para o Estado a sincronização dos tempos urbanos, em virtude de que todas as lógicas e interesses sejam levados em conta quando da realização de investimentos e mutações legais na forma de deste setor da cidade. Para que neste novo plano do CBD que se encontra em estado de articulação e construção não sejam excluídos novamente setores chaves da vida urbana.

Por outro lado, ressalte-se a responsabilidade que tem o aparelho estatal de modernizar e integrar os diferentes organismos e instrumentos de gestão do uso do solo. Até o momento, as diversas falhas presentes no desenvolvimento da cidade pela utilização de lógicas fragmentadas e superpostas entre si têm sido responsáveis por um processo constante de modernização da cidade com bases pouco sólidas.

\section{REFERÊNCIAS}

Barco de Botero, C. e M. Smolka (2000) Desafios para implementar la "participación en plusvalías" en Colombia. Landlines: Newsletter of the Lincoln Institute of Land Policy, v. 12, n. 2. Disponível em http://www.lincolninst.edu/pubs/ PubDetail.aspx?pubid=308. Acesso em 10 de fevereiro de 2005.

BRASIL (2001) Lei Federal n. 10.257 (Estatuto da Cidade), de 10 de julho de 2001. Estabelece diretrizes gerais da política urbana.

Doebele, W.A. (1998) La recuperación de plusvalías "socialmente creadas" en Colombia. Landlines: Newsletter of the Lincoln Institute of Land Policy, v. 10, n. 4. Disponível em http://www.lincolninst.edu/pubs/PubDetail.aspx?pubid=953. Acesso em 10 de fevereiro de 2005.

Jaramillo, S. (2001) La experiencia colombiana en la recuperación estatal de los incrementos del precio del suelo. La contribución de valorización y la participación en plusvalías. In Smolka, M. e F. Furtado (eds.) Plusvalias en América latina: alternativas para el desarrollo urbano. Lincoln Institute of Land Policy / EURE Libros, Santiago.

Lopes, R. (1998) A cidade intencional: o planejamento estratégico de cidades. Mauad, Rio de Janeiro.
Martinez, L.R. (2004) Instrumentos de ordenamiento territorial urbano: conceptos, processo legal y articulación. Universidad Nacional de Colômbia, Bogotá.

Parias, A. e A. Luna (2002) Transporte y procesos urbanos em el siglo XX: Bogotá y la Bahia de Cádiz vistos com el mismo prisma. Departamento de Publicaciones / Universidad Externado de Colombia, Bogotá.

Smolka, M. e D. Amborski (2001) Captura de mais-valias para o desenvolvimento urbano: uma comparação interamericana. In Abramo, P. (org.) Cidades em transformação: entre o plano e o mercado. Experiências internacionais em gestão do solo urbano. IPPUR-UFRJ, Rio de Janeiro.
Johann Dilak Julio Estrada (johann.estrada@pucpr.br) Fábio Duarte (duarte.fabio@pucpr.br)

Artigo recebido em 13/01/2006 e aprovado em 23/04/2006. 